\title{
Rapid Implementation of a Novel Embedded Senior Medical Student Program, as a Response to the Educational Challenges of COVID-19
}

\author{
*Jennifer May ${ }^{a}$, Miriam Grotowski ${ }^{a}$, Tim Walker ${ }^{a b}$ \& Brian Kellyac \\ a: University of Newcastle, Australia; b: Calvary Mater Newcastle Hospital, Australia; \\ c: University of New England, Australia
}

\begin{abstract}
As with many OECD countries, graduating medical students have been choosing specialist careers at a greater rate than ever before. Generalism in the form of family (general practice) and more generalist medical specialties have been trending down resulting in distributional geographic challenges. With the advent of COVID-19 in March 2020, medical schools and in particular the Joint Medical Program situated in a regional and rural area in NSW Australia had the unique opportunity to rethink the penultimate year curriculum when the previous rapid rotation model through numerous medical specialities became untenable. The need to vision a new practical pragmatic curriculum spurred a rapid revaluation of assessment, placement length and model with a pivot to an "embedded senior student placement" agnostic of discipline and supported by a competency-based learning portfolio. This article explores the barriers and enablers and identifies the potential elements of this type of placement which can be adapted to community and smaller rural sites. The positive student and supervisor experience also enabled an employment model to be woven into the students learning and ensured on hand medical student workforce for hospitals throughout the rural footprint. The capacity of these placements to celebrate variation in experience and support students to learn on the job have now caused a revision of the penultimate year with expectation of gains in students' satisfaction and in employability. It has also opened up options to deliver and increase the inherent value of generalist placements with likely long term workforce benefit.
\end{abstract}

Keywords: Assistants in Medicine; COVID-19 impact; generalism; longitudinal placement; work-based assessment

\section{Background}

As in many Organisation for Economic Co-operation and Development (OECD) countries, graduating medical students in Australia have been choosing specialist careers at a greater rate than ever before (Playford et al., 2020). Generalism in the form of family (general) practice and more generalist medical

*Corresponding Author: Professor Jennifer May, Director University of Newcastle Department of Rural Health, University of Newcastle, 114-148 Johnston St Tamworth NSW 2340 Australia.

Email: jennifer.may@newcastle.edu.au

Journal URL: https://publications.coventry.ac.uk/index.php/pblh

May, J., Grotowski, M., Walker, T., \& Kelly, B. (2021). Rapid implementation of a novel embedded senior medical student program, as a response to the educational challenges of COVID-19. International Journal of Practice-based Learning in Health and Social Care, 9(2), 63-73. DOI 10.18552/ijpblhsc.v9i2.736

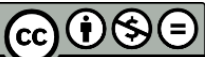

BY NC ND (C) 2021 Jennifer May, Miriam Grotowski, Tim Walker \& Brian Kelly. This Open Access article is distributed under the terms of the Creative Commons Attribution Attribution-Non-Commercial No Derivatives 4.0 International License (https://creativecommons.org/licenses/by-nc-nd/4.0/ ), which permits unrestricted non-commercial use, distribution, and reproduction in any medium, provided the original work is properly cited and is unaltered. 
specialities have been trending down in popularity and visibility, resulting in geographic maldistribution of graduands and potential adverse impacts on the provision of holistic care (Medical Deans of Australia and New Zealand., 2020).

While there is little doubt that exposure to generalism and longitudinal care within most medical student curricula has been reducing over time (Albritton et al., 2006), some innovative responses have emerged. Longitudinal Integrated Clerkships (LICs) have been one such response, with many of the pioneer programs of this approach in North America, South Africa and Australia over the last 50 years being small, rurally or community-based, and conducted in the penultimate year of training (Worley et al., 2016). Here we report the large-scale and rapid implementation of a LIC-like Embedded Senior Medical Student Program (ESMS) for final year medical students studying at two universities across six rural and urban clinical schools in response to the COVID-19 pandemic. Following this accelerated implementation, these placements became the sole pathway leading to graduation from the Joint Medical Program of the University of New England and the University of Newcastle in 2020.

Figure 1.

Map depicting the footprint of the University of Newcastle Joint Medical Program. Reproduced with permission of the authors.

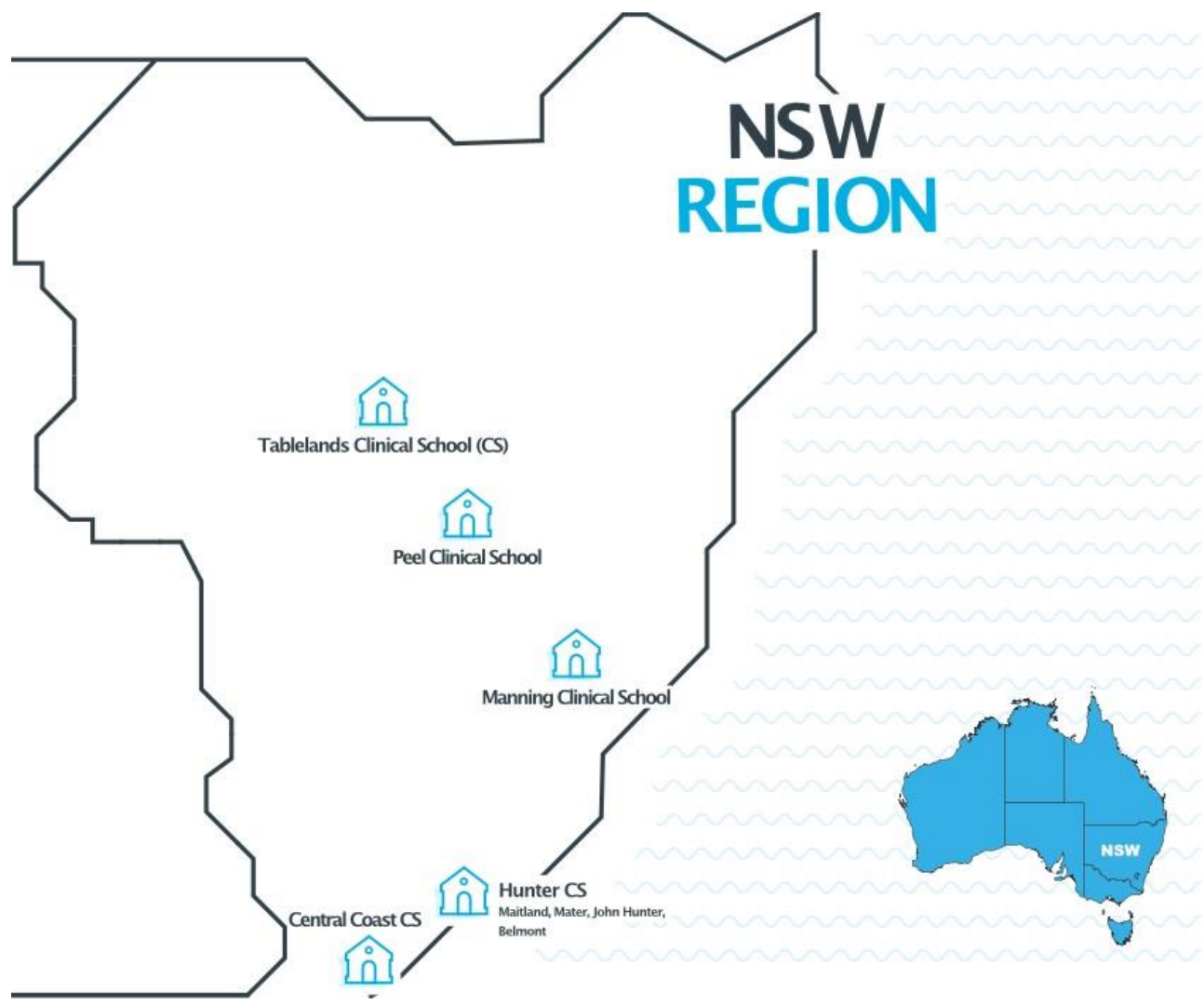

The University of Newcastle and The University of New England offer a 5-year undergraduate entry Medical Program that delivers equitable curriculum content, known as the Joint Medical Program (JMP). The JMP is one of eight undergraduate entry medical programs in Australia. The University of Newcastle commenced its original undergraduate program in 1978 in Newcastle, a large regional centre of 250000 located on the New South Wales (NSW) north coast, 200km from Sydney. It has a reputation for socially accountable medical education (Powis \& Rolfe, 1998) and has graduated a significant proportion of Australia's Indigenous doctors (Holliday et al., 2015). The JMP has been transitioned from a Bachelor level course (B. Med) to a combined undergraduate and graduate degree (BMedScMD) at Level 9 in the 
Australian Qualifications Framework (Australian Qualifications Framework, 2013). The first students are due to graduate from the new program at the end of 2021.

From its inception, the JMP has also had a strong commitment to rural communities and in 2008 formed a partnership with the University of New England, based in a more rural region to the North. Students spend the first three years of the five-year course based in either Newcastle or Armidale with further clinical exposure in years four and five on six clinical school sites in the footprint (Figure 1). The sites differ in size from the John Hunter Hospital with 80-90 students per year level to smaller clinical schools with 10-15 students. In 2020, there were 160 final year medical students spread across these six clinical schools, requiring placement in order to graduate.

This article will explore the enablers and barriers to the transition by the JMP to longitudinal final year placements and our initial experience with large scale implementation.

\section{The rapid curriculum review and change}

As with many medical schools, faculty from the JMP faced significant disruption to learning opportunities in clinical settings with the onset of the COVID-19 pandemic. In March 2020, the two Local Health Districts that have responsibility for hospital services in the JMP footprint indicated significant reservations about student placements' safety. Concerns related to the availability of personal protective equipment (PPE) and the difficulties in physically distancing in clinical locations, and thus the number of clinicians and students that could safely attend ward rounds and clinical meetings at any one time. This culminated in a pause to all student clinical activities for a fortnight. Early on, the State Department of Health of NSW also expressed interest in working with universities to fast-track final year medicine and nursing students towards graduation as a reserve workforce capacity.

The Universities of Newcastle and New England had the unique opportunity to rethink the final year curriculum. The previous short, block-based rotations through numerous medical specialities became untenable in March 2020 with the advent of COVID-19. Most clinical sites withdrew clinical placements due to the consequent elevated infectious risk to patients, staff and students. The need to find a novel and pragmatic curriculum that would allow genuine patient-based student learning while reducing transmission between students and others spurred a rapid revaluation.

The notion of an embedded medical student program was reviewed. Assessment, placement length, and the instructional model were all incorporated into a longitudinally integrated ESMS placement. The ESMS was agnostic of discipline and supported by a competency-based learning portfolio. This could be considered a LIC-like Amalgamative Clerkship under Worley's "typology” of LICs (Worley et al., 2016, p. 922).

The principles underpinning and informing this rapid redesign reflected the commitment to a competency and capability-based curriculum (Dornan et al., 2019; Wass et al., 2001). The application of these new capability-based teaching and assessment methods became a more flexible model of practice-based teaching in this final phase of the curriculum. The ESMS also met the health 'services' needs to both adapt to a COVID-19 environment while building readiness for practice in our pre-graduation students. The framework of experience-based learning to drive capability was influential in shaping this model (Dornan et al., 2019). This model incorporates the core elements of preparation (through detailed attention to orientation and clinical preparedness); experience (through the opportunity for more authentic practicebased, real-world experience embedded as a contributing member of the clinical team); reflection (supported by the opportunity for structured teaching and learning sessions, such as dedicated and facilitated student reflection sessions and a focus on professionalism); and performance (including competency and workplace-based assessment and practice-based learning portfolios). Such a framework, we believe, provides an appropriate and flexible approach to progress students in the complex and rapidly changing clinical and educational environment brought about by COVID-19 and provides the potential for an enhanced junior doctor-preparedness among graduands (Fraser \& Greenhalgh, 2001).

Further support for the implementation of new models of practice-based learning was also evident at a jurisdictional level, with guidance from the Australian Medical Council (AMC) and Australian Health 
Practitioner Registration Authority (AHPRA). There was a desire to rapidly accredit necessary changes to medical school course delivery and a willingness to work with organisations to avoid delays to graduation (Australian Medical Council, 2020).

Faculty first identified the following fundamental design principles of this alternate model in March 2020:

All students would be offered clinical exposure, with a balance between personal safety and health service requirements. Initially, students were not placed in high-risk environments such as critical care, operating theatres and emergency departments. As risks were better understood and mitigated, this was reevaluated.

Rather than being allocated to a block-based discipline rotation, students were paired with Junior Medical Officers (JMOs), with a single student assigned to each JMO. These JMOs had also had their rotations altered by health services to a single ward environment, reducing potential transmission risk.

Planned B. Med assessment components rapidly evolved towards a competency and capability-based assessment model applicable across these diverse clinical placements, assessing core clinical skills and attributes via workplace-based assessments (WBAs) (Frank et al., 2010; Norcini \& Burch, 2007). Applying competency-based principles of an outcomes-based approach to assessment, as recommended by Frank et al. (2010), supervisors were required to complete WBAs. These were completed by clinical supervisors. Other assessment tasks, usually conducted in the B. Med final year, were significantly modified to allow their completion in a socially distanced manner and without significant disruption to clinical placements.

Flexibility was given to each clinical school to adapt student placement experience to local capacity and clinical acceptability. However, the agreed principles of the modified final year and its framework of competency and capability-based assessment with core skills development were assessed similarly across the JMP.

The duration of clinical placements was significantly increased, thus reducing students' movement between different clinical teams and locations. This also promoted students being embedded as a member of the clinical team over a longer period. This built the opportunity for students to more actively contribute to the clinical teams' teams' work and supported greater ownership of student learning by clinicians. Enhanced longitudinal feedback to students highlighting areas for development allowed a more authentic evaluation of the 'students' progress towards graduation and is in line with Boud's recommendation of feedback to enhance learning (Boud, 2015).

The new framework based on these principles involved an intensive two-week construction period, during which a new program design and structure were developed, ready for a rapid implementation which comprised the following steps: An orientation and pre-placement, one-week boot camp was provided to all final year students at their sites, adapted to the needs of the learners at each location. This went some way to meet the immediate need for students to develop practical skills and knowledge to contribute usefully to their clinical teams.

The program, usually delivered to commencing interns (junior medical doctors), was rapidly reframed, locally contextualised and ran on all sites before the new placements commencing. This included documentation and procedural skills, expectations of the new final year student role, approaches to common clinical situations and emergencies, and an introductory understanding of key hospital systems and policies, particularly those relevant to COVID-19, including effective use of PPE. The boot camp was very well received by both students and health service clinicians, who then reported additional confidence in the safety and added benefit of students to their clinical environments from the commencement of the new placements.

Collaboration was undertaken with similar medical schools across New South Wales to share assessment tools, COVID-19 response and curriculum models. The workplace-based assessments were adapted from those developed at Western Sydney University by Tobin and colleagues (Ten Cate et al., 2017). Much of this liaison was achieved through collaboration in an online forum supported by the Medical Deans of 
Australia and New Zealand (MDANZ) and gave our senior university authorities greater confidence that this shared approach would be acceptable to national accreditation bodies. The beneficial effects of the pandemic in breaking down barriers between institutions and encouraging greater collaborative effort has been well documented elsewhere (Brown \& Finn, 2020).

The embedded clinical exposure attached to a JMO led to rethinking the usual medical student role and rostering. The students' placement hours depended on the JMO roster and locale. This varied from our usual final year terms to include acute medical terms, paediatrics, psychiatry and surgical subspecialties, and other traditionally 'non-final-year' clinical teams, such as hospital in the home. Following the commencement of the new model, the total placement duration was 18-22 weeks. Most sites divided this into 2-3 rotations of 7-9 weeks. As hospitals returned to a more normal situation, most students could attend Emergency Department placements. Not all students were able to gain face-to-face experience in critical care units, so a program of simulation, including airways skills, basic life support and detection and care of the deteriorating patient, was developed. This allowed students' competency in key critical care skills to be solidified and assessed. Additional to this clinical exposure, our health services recruited some students into paid Assistant in Medicine (AIM) roles, where the hours worked varied between 4-32 hours per week and involved ward and emergency department (ED) work, both in and after hours, under a shared responsibility model between the JMP and the health services. The level of supervision expected for students in clinical environments was delineated, based upon the existing AHRPA definitions familiar to clinicians, to avoid confusion (Medical Board of Australia (AHPRA), 2020). The requirement for level 1 supervision identified that the (JMO or senior) doctor took direct and principal responsibility for each patient. A doctor was required to be physically present in the ward or ED at all times when the student was providing clinical care. The student needed to consult the doctor about the management of all patients for any episode of care. Supervision via telephone contact or other telecommunications was not permitted. These rules were explained to students, JMOs, senior doctors and nursing staff at each clinical school before each placement commencing. Any issues or concerns raised were dealt with by a combined approach involving clinical, academic and hospital management staff at each site and reported on via JMP and health service governance systems.

A competency and capability-based learning portfolio, concentrating on activities, skills and exposures necessary for safe intern practice, was rapidly developed in booklet format and provided to all students at the commencement of their placements. This method of recorded continuous assessment is now widely used in medical undergraduate medical programs (Ten Cate et al., 2017). The JMP learning portfolio included logs of procedures performed, investigations interpreted, communication tasks completed, and urgent clinical reviews seen by the student together with their JMO. It also recorded any workplace-based assessments of performance (completed by senior doctors during the placement) and supervisor assessments. The contents of the portfolio can be seen in Table 1 .

Collaboration and support across universities through Medical Deans of Australia and New Zealand (MDANZ) allowed consensus-based approaches to content validity and reliability and the mapping of all measured competencies and capabilities to an agreed inventory of required skills for graduating medical students commencing internships in Australia and New Zealand. This remains an area of ongoing work and collaboration (Medical Deans Australia and New Zealand, 2020).

A program of structured teaching was provided with the agreed release of students from their clinical team responsibilities for at least one day per week (to include face-to-face small group student well-being sessions and a program of relevant teaching using Zoom-based methods to ensure access to teaching sessions across all sites (Wilcha, 2020).

The JMP realised the potential of these rapid curriculum changes to impact student well-being. A student well-being curriculum was designed to encourage faculty consideration and prioritise direct teaching centred around skills to enhance student well-being. A well-being policy was developed that recognised optimising student well-being within the Embedded Senior Medical Students program (ESMS) and would ensure a safe and effective experience for these final year students (School of Medicine and Public Health, 2019). Attention to student well-being, including dealing with uncertainty, coping with moral hazard and managing the changing roles, was imperative. The curriculum was rapidly developed, informed by the current literature on well-being. It included the particular components suggested by the 
Australian Medical Student policy document on well-being (Australian Medical Student Association [AMSA], 2018) and the Consensus statement on medical student well-being - Australian and New Zealand Deans (Kemp et al., 2019).

Table 1.

Learning portfolio components for Embedded Senior Medical Students

\begin{tabular}{|l|l|l|l|l|}
\hline $\begin{array}{l}\text { Learning portfolio } \\
\text { component }\end{array}$ & Assessment type & $\begin{array}{l}\text { Typical number } \\
\text { completed }\end{array}$ & Assessor & Description or example \\
\hline Investigations Log & Low stakes/formative & 20 - to 40 & Any doctor & $\begin{array}{l}\text { Review a Chest X-ray on a patient; } \\
\text { record your impression, then discuss } \\
\text { with JMO }\end{array}$ \\
\hline Procedures log & Low stakes/formative & 15 to 30 & Any doctor & $\begin{array}{l}\text { Perform intravenous cannulation under } \\
\text { the direct supervision }\end{array}$ \\
\hline $\begin{array}{l}\text { Communication } \\
\text { Task Log }\end{array}$ & Low stakes/formative & 30 to 50 & Any doctor & $\begin{array}{l}\text { Make a file note documenting a ward } \\
\text { round visit to a patient (countersigned } \\
\text { by a doctor) }\end{array}$ \\
\hline Ward Calls Log & Low stakes/formative & 10 to 30 & Any doctor & $\begin{array}{l}\text { Complete an initial clinical assessment } \\
\text { requested for a patient complaining of } \\
\text { pain }\end{array}$ \\
\hline $\begin{array}{l}\text { Workplace-based } \\
\text { assessment }\end{array}$ & Higher stakes & 8 to 12 & $\begin{array}{l}\text { Senior } \\
\text { doctor }\end{array}$ & $\begin{array}{l}\text { Present a new patient on a ward round, } \\
\text { including clinical assessment, patient } \\
\text { priorities and management }\end{array}$ \\
\hline $\begin{array}{l}\text { Supervisor term } \\
\text { assessment }\end{array}$ & Higher stakes & 3 & $\begin{array}{l}\text { Senior } \\
\text { doctor }\end{array}$ & $\begin{array}{l}\text { Formal assessment at a set point of the } \\
\text { term by senior ward service clinician of } \\
\text { student clinical performance and JMO } \\
\text { readiness }\end{array}$ \\
\hline $\begin{array}{l}\text { Required } \\
\text { competencies }\end{array}$ & Hurdle & 10 & $\begin{array}{l}\text { Required online learning modules for } \\
\text { hospital staff on personal protective } \\
\text { equipment }\end{array}$ \\
\hline
\end{tabular}

\section{Discussion}

Despite its many challenges and difficulties, the rapid emergence of COVID-19 and its impact on practice-based teaching has prompted a productive re-examination by medical schools and health services of the important role of clinical placements. This has been a powerful reminder of the need for a shared commitment to quality practice-based learning in supporting graduates to develop the skills necessary for future practice (van der Vleuten et al., 2012). In our experience, COVID-19 was an effective catalyst propelling the rapid design of competency and capability-based framework and innovative assessment tools, and the implementation of these across diverse clinical and geographic settings. For students, staff and the broader health system, this also provided a case study in the necessity of adaptability responding to a crisis in a way that builds new skills, enhances future individual and system capabilities, and adapts to local priorities and emerging needs. By increasing student engagement in this process, there are opportunities to improve their transformative learning (Van Schalkwyk et al., 2019).

COVID-19 has left an evident legacy for the program, which will require further reflection and evaluation. The rapid implementation of an extended placement model, the pivot to a different assessment format, the integration of paid work and student exposure, and student experience's heterogeneity are all changes that merit further examination. This pivot is accommodating the need for a greater focus on generalism and context. 
The positive working relationships between health services and the JMP forged in response to COVID19 , led to a shared redesign of the curriculum to emphasise skills more closely and visibly aligned to health service and community needs, and supported students toward graduation. This aligns well with the vision of the Lancet Commission's report on the future of Health Professionals' Education (Frenk et al., 2010). The challenge presented by COVID-19 served to focus the significance of the interdependency of health professional education and health systems. This provided a catalyst to a more transformative approach to learning to develop a deeper set of capabilities relevant to the current and future health system needs. These discussions, realisations and relationships also pave the way for closer collaboration and work readiness initiatives into the future.

Students reported high levels of student satisfaction with placements, with a perception of more authentic and meaningful engagement with clinical teams and a sense of making a positive contribution. The latter provided defined and explicit support for students to undertake clinical roles within their scope of training and practice (e.g., basic documentation and some simple procedures under supervision). The partnership with JMOs also provided students with near-peer support and the capacity for assistance with both the clinical and academic workload. An important lesson was the need to ensure adequate supervisory support to the JMOs in this role, some of whom reported limited confidence initially with students amid concerns about their own teaching and learning needs being overlooked by the focus on COVID-19.

'Soft skills' (soft knowledge), such as teamwork and mutual respect (Parboosingh, 2002), were recognised and valued by students, who felt essential and useful contributors to the delivery of health care, and thus were better able to contextualise the utility of these skills. Kaufman (2019) notes that such tacit knowledge is best acquired through being embedded in a practice community, participating in processes and reflecting on challenging events. In the formal evaluation of the Assistants in Medicine Program, students reported enhanced confidence and pride in teamwork and valued contribution (New South Wales Health, 2021)

The recognition of student well-being within the curriculum in explicit and implicit ways has been a welcome fruit of 2020. Shared responsibility models between health services and universities for medical student well-being had not been previously contemplated nor welcomed, but 2020 led to a new approach. The synergistic value of supporting practitioner well-being, starting from medical students and continuing into JMO years, is also fertile ground for future collaboration. There is interest from regularity authorities, employers and universities in a longitudinal and explicit approach to ongoing challenges they have in enhancing the well-being of junior medical staff (Australian Medical Association, 2021).

The extended student placements and their more varied locations provided greater exposure to generalism. There was opportunity for students to experience smaller sites in greater depth and for faculty to consider extending the ESMS to smaller rural sites, including rural general practice. The need for more placement opportunities led to a diversifying of student experience across a range of clinical locations and settings outside traditional larger teaching hospital speciality rotations, in line with Longitudinal Integrated Clerkships (Worley et al., 2016). This enriched and broadened the learning opportunities and encouraged students to consider internship employment within smaller regional centres. This was not without challenges, requiring shifting of expectations of students (and some clinicians) regarding what constitutes a high-value clinical placement. This reflected a bias towards the perceived high-status rotations (e.g., medical and surgical subspecialties) in contrast to placements in other terms (e.g., aged care and rehabilitation), despite the clear learning value of the latter terms.

Many of the barriers encountered reflect challenges in transitioning from a traditional time-based practice learning model to an outcome or competency-based framework (Snell \& Frank, 2010). Clinical engagement in these new assessment tools (and their rapid introduction) and the relationship between the clinical supervisors and students came into sharp focus. Some clinicians were already fatigued by the increased workload of COVID-19, being further challenged by request for higher levels of supervisor engagement. However, once clinicians realised that students in their new roles, with sufficient support, could be a key part of the team and contribute to clinical services, their level of engagement in the learning processes increased. 
The JMP and the national medical school registration authorities were able to accommodate a streamlined and pragmatic governance structure for course changes and rapid curriculum review. Weekly meetings of key academic staff and clinical site leads regarding their placement needs and constraints better met the challenges encountered in a continuing clinical placement in highly changeable and COVID-19 affected clinical settings.

The workplace-based assessment was chosen as a method that reflected the competency and capabilitybased curriculum framework (Norcini \& Holmboe, 2010). It had high face validity (for both students and supervisors), given the focus on practice-based learning, and provided the tools to assess the developing pre-intern capabilities discussed above (Schuwirth \& Van der Vleuten, 2011). Such a model, utilising student learning portfolios, also promoted student ownership of their learning and enhanced transparency of their progress in meeting assessment requirements. The focus on transferable skills and attitudes also provided a means to address student concerns about the diversification of placements, by clearly indicating that the required general clinical skills and professional attributes could be acquired across diverse clinical placement settings and diverse patient populations. This model also emphasised the supervisor's pivotal role and the program's trust in their judgment about student performance, reflecting the shared commitment to student outcomes.

Students and clinical supervisors were able to forge deeper working relationships, contributing to clinical care and working together more collaboratively to devise student-tailored learning plans. Giving supervisors autonomy in this process led to them owning their students' learning and well-being, and they provided greater personal and professional support and encouragement. The JMP will be doing further research in this area.

One abiding concern was around the previously documented "failure to fail", reported to occur using competency-based assessment tools (Dudek et al., 2005; Nixon et al., 2016). While this can be a challenge wherever such practice-based assessments are in use, especially with close supervisory relationships, this was mitigated by the steps taken at each local clinical school site to orient and engage supervisors. The embedded nature of the practice-based learning and placements, with students as a junior member of the clinical team, provided increased opportunities to identify concerns about student performance in clinical environments. Our local region has had the experiential benefit of implementing a comprehensive program of workplace-based assessment for international medical graduates (Nair et al., 2017) (alongside the familiarity with its use in postgraduate training programs in Australia), with many clinical supervisor's familiar with and educated in these methods. Furthermore, the JMP conducts professional development in WBA and provision of feedback within a Certificate in Clinical Teaching and Supervision (an initiative of the JMP's Academy of Clinical Educators). This has assisted in developing clinicians' confidence in the use of competency-based assessments. Despite these mitigating steps, concerns about ensuring there is appropriate, real and timely feedback to students, along with accurate summative assessment evaluation and effective remediation, remain.

\section{Conclusion}

The new approach to the capstone year in our undergraduate medical course, described above, came out of the compelling need to revamp and review placement structures in light of COVID-19. This has led to the adoption of longitudinal placements as our primary final year model, assessing core, intern-readinessbased clinical competencies and capabilities via a learning portfolio.

The positive student and supervisor experience to this redesign and the greater integration of student learning with clinical care enabled an employment model to be woven into the students' learning. This ensured an on-hand medical student workforce for hospitals throughout the program's rural and urban footprint. The capacity of these placements to celebrate variation in experience and support students to learn on the job has now led to a permanent revision of the final year curriculum, with the expectation of further gains in student workforce readiness and satisfaction with clinical placements. It has accelerated a move towards online learning and assessment and facilitated a collegiate and diverse approach across multiple sites and contexts. Clinical supervisors have assumed a key role in the development of content and the assessment of learning outcomes attained. 
Shared interests between health services and universities have been emphasised, with the common goal of graduating well equipped and capable students. This interest in supporting work-ready students has led to health services organising and facilitating work readiness boot camps and other practical activities. This shared teaching responsibility has been realised.

Finally, the move to the capstone competency-based assessment and extended exposures opens the door to generalist placements distributed more widely across urban, regional, and rural locations, thereby equipping students for diverse healthcare environments where they will work. This helps combat the perceived lower status of such locations and placements. These changes allow the JMP to be in sync with national medical workforce policy and ensure a key role in building the future workforce.

\section{Acknowledgements}

The authors acknowledge and commend the key collaborators in this rapid curriculum project. Colleagues working in the Joint Medical Programme gave countless hours of development and support. The NSW Ministry of Health working through the HNE Local Health District and Central Coast Local Health District were instrumental in supporting the changed working arrangements. Clinical Deans at each site and the clinical supervisors provided the hands-on supervision and the network of medical Deans in NSW and, in particular, Dr Stephen Tobin from University of Western Sydney were very generous with their support.

\section{Sources of funding}

No additional funding was required for this project. Staff employed in The Joint Medical Programme are funded through their parent universities. In addition staff in rural sites receive funding from the Australian Department of Health through the Rural Health Multidisciplinary training Programme.

\section{ORCID}

Jennifer May

Miriam Grotowski

https://orcid.org/0000-0002-3728-4313

Tim Walker

https://orcid.org/0000-0001-8823-2284

Brian Kelly

https://orcid.org/0000-0001-7034-1327

https://orcid.org/0000-0003-4460-1134

\section{References}

Albritton, W., Bates, J., Brazeau, M., Busing, N., Clarke, J., Kendel, D., McClean, K., Saucier, D., Waddington, A., Walker, D., \& Gray, J. (2006). Generalism versus subspecialization: Changes necessary in medical education. Canadian Journal of Rural Medicine, 11(2), 126-128. https://pubmed.ncbi.nlm.nih.gov/16630441/

Australian Medical Association. (2021). Doctors 4 Doctors. https://www.drs4drs.com.au/

Australian Medical Council. (2020). Accreditation and Covid-19. https://www.amc.org.au/accreditationand-covid-19/

Australian Medical Student Association. (2018). Mental health and Wellbeing policy. https://www.amsa.org.au/sites/amsa.org.au/files/Mental\%20Health\%20and\%20Wellbeing\%20P olicy\%20\%282018\%29.pdf

Australian Qualifications Framework. (2013). AQF levels. Australian Qualifications Council https://www.aqf.edu.au/sites/aqf/files/aqf-2nd-edition-january-2013.pdf

Boud, D. (2015). Feedback: Ensuring that it leads to enhanced learning. The Clinical Teacher, 12(1), 3-7. https://doi.org/10.1111/tct.12345

Brown, M. E. L., \& Finn, G. M. (2020). Intra-COVID collaboration: Lessons for a post-COVID world. Medical Education, 55(1), 122-124. https://doi.org/10.1111/medu.14366

Dornan, T., Conn, R., Monaghan, H., Kearney, G., Gillespie, H., \& Bennett, D. (2019). Experience based learning (ExBL): Clinical teaching for the twenty-first century. Medical Teacher, 41(10), 10981105. https://doi.org/10.1080/0142159x.2019.1630730 
Dudek, N., Marks, M., \& Regehr, G. (2005). Failure to fail: The perspectives of clinical supervisors. Academic Medicine, 80(10 Supplement), S84-S87. https://doi.org/10.1097/00001888200510001-00023

Frank, J. R., Snell, L. S., Ten Cate, O., Holmboe, E. S., Carraccio, C., Swing, S. R., Harris, P., Glasgow, N. J., Campbell, C., Dath, D., Harden, R. M., Iobst, W., Long, D. M., Mungroo, R., Richardson, D. L., Sherbino, J., Silver, I., Taber, S., Talbot, M., \& Harris, K. A. (2010). Competency-based medical education: Theory to practice. Medical Teacher, 32(8), 638-645. https://doi.org/10.3109/0142159X.2010.501190

Fraser, S. W., \& Greenhalgh, T. (2001). Coping with complexity: Educating for capability. British Medical Journal, 323(7316), 799-803. https://doi.org/10.1136/bmj.323.7316.799

Frenk, J., Chen, L., Bhutta, Z. A., Cohen, J., Crisp, N., Evans, T., Fineberg, H., Garcia, P., Ke, Y., Kelley, P., Kistnasamy, B., Meleis, A., Naylor, D., Pablos-Mendez, A., Reddy, S., Scrimshaw, S., Sepulveda, J., Serwadda, D., \& Zurayk, H. (2010). Health professionals for a new century: Transforming education to strengthen health systems in an interdependent world. The Lancet, 376(9756), 1923-1958. https://doi.org/10.1016/S0140-6736(10)61854-5

Holliday, V., O'Mara, P., \& Watts, A. (2015). The Miroma Bunbilla Pre-entry to Medicine program for Aboriginal and Torres Strait Islander people. LIME Good Practice Case Studies, 3, 24-30. http://www.limenetwork.net.au/wp-content/uploads/2018/12/HOLLIDAY-GPCS-3.pdf

Kaufman, D. (2019). Teaching and learning in medical education: How theory can inform practice. In T. Swanwick, K. Forrest, \& B. O’Brien (Eds.), Understanding Medical Education (3rd ed., pp. 3769). John Wiley \& Sons.

Kemp, S., Hu, W., Bishop, J., Forrest, K., Hudson, J., Wilson, I., Teodorczuk, A., Rogers, G., Roberts, C., \& Wearn, A. (2019). Medical student wellbeing-A consensus statement from Australia and New Zealand. BMC Medical Education, 19, Article Number 69, 1-8. https://doi.org/10.1186/s12909-019-1505-2

Medical Board of Australia (AHPRA). (2020). Supervised practice for international medical graduates. https://www.medicalboard.gov.au/Codes-Guidelines-Policies/Supervised-practiceguidelines.aspx

Medical Deans Australia and New Zealand. (2020). Medical Schools Outcomes Database -National Data Report 2020, 2015-2019 Data from Final Year Medical Students at Australian medical Schools. https://medicaldeans.org.au/md/2020/08/2020-MSOD-National-Data-Report_2015-2019-Fullreport.pdf

Medical Deans Australia and New Zealand. (2021). Working Groups of the Medical Education Collaboration Committee, Assessment Projects Working Group https://medicaldeans.org.au/priorities/medical-education

Nair, B. R., Moonen-van Loon, J. M. W., Parvathy, M., Jolly, B. C., \& van der Vleuten, C. P. M. (2017). Composite reliability of workplace-based assessment of international medical graduates. Medical Journal of Australia, 207(10), 453-453. https://doi.org/10.5694/mja17.00130

New South Wales Health (NSW). (2021). Assistants in Medicine Evaluation Report. https://www.health.nsw.gov.au/workforce/medical/Pages/aim-evaluation-report.aspx

Nixon, L. J., Gladding, S. P., \& Duffy, B. L. (2016). Describing failure in a clinical clerkship: Implications for identification, assessment and remediation for struggling learners. Journal of General Internal Medicine, 31(10), 1172-1179. https://doi.org/10.1007/s11606-016-3758-3

Norcini, J., \& Burch, V. (2007). Workplace-based assessment as an educational tool: AMEE Guide No. 31. Medical Teacher, 29(9-10), 855-871. https://doi.org/10.1080/01421590701775453

Norcini, J., \& Holmboe, E. (2010). Work based assessment. In P. Cantillon \& D. Wood (Eds.), ABC of Learning and Teaching in Medicine ( $2^{\text {nd }}$ pp. 48-51). Blackwell Publishing.

Parboosingh, J. T. (2002). Physician communities of practice: Where learning and practice are inseparable. Journal of Continuing Education in the Health Professions, 22(4), 230-236. https://doi.org/10.1002/chp.1340220407

Playford, D., May, J. A., Ngo, H., \& Puddey, I. B. (2020). Decline in new medical graduates registered as general practitioners. Medical Journal of Australia, 212(9), 421-422. https://doi.org/10.5694/mja2.50563

Powis, D. A., \& Rolfe, I. (1998). Selection and performance of medical students at Newcastle, New South Wales. Education for Health, 11(1), 15. 
School of Medicine and Public Health. (2019). Wellbeing Principles for Embedded Senior Medical Students. University of Newcastle, Australia.

Schuwirth, L. W., \& Van der Vleuten, C. P. (2011). Programmatic assessment: From assessment of learning to assessment for learning. Medical Teacher, 33(6), 478-485. https://doi.org/10.3109/0142159X.2011.565828

Snell, L. S., \& Frank, J. R. (2010). Competencies, the tea bag model, and the end of time. Medical Teacher, 32(8), 629-630. https://doi.org/10.3109/0142159X.2010.500707

Ten Cate, O., Tobin, S. A., \& Stokes, M.-L. (2017). Bringing competencies closer to day-to-day clinical work through entrustable professional activities. Medical Journal of Australia, 206(1), 14-16. https://doi.org/10.5694/mja16.00481

van der Vleuten, C. P., Schuwirth, L. W., Driessen, E. W., Dijkstra, J., Tigelaar, D., Baartman, L. K., \& van Tartwijk, J. (2012). A model for programmatic assessment fit for purpose. Medical Teacher, 34(3), 205-214. https://doi.org/10.3109/0142159X.2012.652239

Van Schalkwyk, S. C., Hafler, J., Brewer, T. F., Maley, M. A., Margolis, C., McNamee, L., Meyer, I., Peluso, M. J., Schmutz, A. M., Spak, J. M., \& Davies, D. (2019). Transformative learning as pedagogy for the health professions: A scoping review. Medical Education, 53(6), 547-558. https://doi.org/10.1111/medu.13804

Wass, V., Van der Vleuten, C., Shatzer, J., \& Jones, R. (2001). Assessment of clinical competence. The Lancet, 357(9260), 945-949. https://doi.org/10.1016/s0140-6736(00)04221-5

Wilcha, R. -J. (2020). Effectiveness of virtual medical teaching during the COVID-19 crisis: Systematic review. JMIR Medical Education, 6(2), e20963. https://doi.org/10.2196/20963

Worley, P., Couper, I., Strasser, R., Graves, L., Cummings, B.-A., Woodman, R., Stagg, P., Hirsh, D., \& the Consortium of Longitudinal Integrated Clerkships (CLIC) Research Collaborative. (2016). A typology of longitudinal integrated clerkships. Medical Education, 50(9), 922-932.

https://doi.org/10.1111/medu.13084 